\title{
LA SOBERANÍA MÁS ALLÁ DE LA INSTANCIA DEL PODER Y DEL DOMINIO EN TORNO A LA BIO-POLÍtica DE JACQUES DERRIDA
}

Iván Trujillo ${ }^{1}$

\begin{abstract}
Resumen: En el presente artículo planteamos la existencia, en el Derrida de La diseminación, de cierto pensamiento sobre la bio-política. Incluyendo la figura animal, este pensamiento es también el pensamiento de una soberanía más allá de la instancia del poder y del dominio. El Seminario La bestia y el soberano publicado postumamente, parece ser su más acabada expresión. En primer lugar, seguimos las indicaciones realizadas por Derrida acerca de la pintura como zôgraphia en La diseminación (1972). La deconstrucción derridiana de lo que llamamos "la secuencia soberana", nos permite analizar la relación entre el problema de "la animalidad de la escritura" y de la soberanía como corolario del pensamiento de una cierta bio-política o zoo-política tempranamente discernida. En segundo lugar, exploramos en algunos de los pliegues de la discusión de Derrida con Agamben y con Foucault sobre el concepto de vida, los términos de una cierta politicidad de la vida que incluye la animalidad y susceptible de ser situada más allá de la instancia del poder y del dominio. Finalmente, y en tercer lugar, tras confrontar los conceptos de soberanía de Foucault y de Derrida a propósito del Leviatán de Hobbes, retomamos el problema inicial de la zôgraphia en relación con la cual buscamos aproximarnos a lo que Derrida va a llamar en el Seminario La bestia y el soberano "la doble y contradictoria figuración".
\end{abstract}

Palabras Clave: Biopolítica. Soberanía. Zôgraphia. Derrida. Foucault.

\section{INTRODUCCIÓN}

Aunque los problemas de la soberanía y de la relación entre la bestia y el soberano sean una de las últimas preocupaciones de la filosofía de Jacques Derrida, creemos posible sostener que estas preocupaciones ya han hecho su aparición en trabajos más tempranos y en términos bastante bien definidos. Uno de estos términos es el problema de la "zôgraphia", es decir el problema de una cierta animalización fundada en la relación entre la pintura, la escritura y el soberano. Una pista sobre esto la da Derrida mismo en El animal que luego estoy si(gui)endo al hablar de una "animalidad de la escritura." (DERRIDA, 2008, p. 69). Nos proponemos mostrar que es sobre la base de este problema,

${ }^{1}$ Profesor visitante en la Universidad de California, Riverside, CA - Estados Unidos de América. E-mail: itrujillocorrea@gmail.com

http://dx.doi.org/10.1590/0101-3173.2018.v41n2.05.p73 
que es también un pensamiento sobre lo vivo, que ha tenido lugar un temprano pensamiento zoo-o o bio-político en Derrida. ${ }^{2}$ Este pensamiento, además, logra tempranamente desfigurar o comprometer la lógica del concepto de soberanía del que hablará más tarde, es decir el problema de la indivisibilidad. Si decimos "zoo-político" o "bio-político", es entonces también para intentar cernir algunos de los términos derridianos que comparecen en la discusión con los análisis y reflexiones contemporáneas en torno a la biopolítica, en particular Foucault y Agamben.

Ahora bien, en el campo de los estudios derridianos, la relación entre la animalidad y la biopolítica tiende a ser tratada por separada, relacionando estrechamente la animalidad con la soberanía y la biopolítica con el problema de la vida. ${ }^{3}$ Creemos que hay razones fundadas para ello, pero es probable que la confrontación de Derrida con Agamben centrada en la necesidad que tiene éste de reconocerle su estatuto moderno a la biopolítica, haya ofrecido condiciones para desalojar el problema de la animalidad del que, sin embargo, es indisociable. En esta discusión, por otra parte, está implicado Foucault, del que Derrida hará notar que no coincide del todo con Agamben. Los estudios mencionados suelen proceder sobre este asunto identificando primero la conceptualidad de Agamben o de Foucault para luego, no sólo identificar el pensamiento derridiano, sino para hacer intervenir deconstructivamente a

\footnotetext{
2 Simone Regazzoni ha estado a punto de decir esto en su escrito Derrida y la deconstrucción de lo biopolítico (REGAZZONI, 2015, p. 221-235).

3 A nosotros nos parece justificado. Pero creemos que el movimiento mismo de la argumentación derridiana, cuando no su expresa indicación, desordena estos encuadres. La relación animalidadsoberanía con prescindencia de la cuestión de la biopolítica, la encontramos por ejemplo en el escrito de Emmanuel Biset Soberania, animalidad y politica (BISET, 2008, p. 125-144). También la encontramos en el texto de Evelyn Galiano Deconstrucción, vida, animalidad. Hay que decir, no obstante, que la misma exposición de la problemática política de la animalidad no deja de encaminarse a la referencia a la biopolítica, si bien de manera implícita y a través de la discusión con Agamben (GALIANO, 2015, p. 115-131). En cuanto a la relación vida - biopolítica con prescindencia de la animalidad, volvemos a encontrar a Emmanuel Bisset en su escrito Deconstrucción de la biopolítica (BISET, 2016, p. 205-222). Aquí el cuestionamiento zoopolítico y espectropolítico cuestionan los límites de la biopolítica y en general las fronteras categoriales estables, por lo mismo que excluye ampliar el concepto de biopolítica hacia estudios de la animalidad, de la monstruosidad y de la espectrología, que no hagan de la política el juego con los límites. Esta exigencia nos parece crucial en el presente artículo. Encontramos también esta prescindencia en el escrito ya mencionado de Simone Regazzoni Derrida y la deconstrucción de lo biopolítico. Hay que decir, como antes pero en sentido inverso, que la misma exposición de la problemática de la biopolítica vuelve la referencia a la animalidad algo ineludible. Y esto, de nuevo, a través de la discusión con Agamben (REGAZZONI, 2015, p. 221-235). Finalmente, el texto de Javier Pavez Vida espectral: deconstrucción y biopolítica, muy concentrado sobre la relación de Agamben con el pensamiento derridiano, echa luces sobre la discusión de Derrida con aquel, rozando siempre la cuestión de la animalidad (PAVEZ, 2015, p. 201-229).
} 
ésta en la conceptualidad de aquéllos. Según un modo de proceder, quizás en el fondo algo defensivo, se busca entonces mostrar cómo la deconstrucción derridiana de la soberanía logra desbaratar, por ejemplo, el historicismo del concepto foucaultiano de poder soberano y su pretensión de situar el pensamiento político de la soberanía como un remanente pre-moderno. Es usual, por lo mismo, que en esta estrategia Agamben sea tomado como el factor propicio y más fallido de este historicismo, al calor de la aspereza con la cual Derrida discute algunas de sus proposiciones. Como también es usual que en esta encarnizada discusión se tomen en cuenta sobre todo los textos inmediatamente concernidos en ella. En lo que siguenos damos una estrategia quizá inversa. Y totalmente exploratoria.

Procedemos así. En primer lugar, dilucidamos en La diseminación los términos de un cierto pensamiento zoo-político o bio-político derridiano a partir de la noción de la relación entre pintura como "zôgraphia", escritura y soberanía. Una secuencia soberana entre la pintura, la escritura y la voz del soberano se ve perturbada tras el seguimiento animal de la escritura. En el trazado de esta animalidad, figura una vida indisociable de la política que, desde temprano, parece comprometer la distinción entre "vida desnuda" y politicidad, como quiere Agamben. Y, en consecuencia también, la biopolítica como fenómeno sólo moderno.

Así entonces, en segundo lugar, enfrentamos la objeción que Derrida realiza en torno a la distinción hecha por Agamben en Homo sacer entre zốe y bios, y sobre la base de una cierta apelación a Foucault de La voluntad de saber. Es una distinción situada en la diferencia entre los griegos y los modernos, y dentro de aquellos, centrada en Aristóteles. Pero para Derrida ni en Aristóteles es segura esta distinción, ni Foucault deja de reconocer el vínculo en Aristóteles entre vida y política, ni Agamben mismo ha dejado de reconocer en Aristóteles la existencia de una zôê no desnuda. Tras señalar que para Derrida los discursos de estos dos autores se dirigen a lo más vivo, a saber, al poder soberano, a la vida y la muerte, a la animalidad, etc., buscamos reconocer el modo en que Derrida reconduce el poder soberano como poder de vida y de muerte en Foucault a una problematización de la instancia del poder y del dominio en dos de sus textos: Más allá del principio del poder y Ser justo con Freud. En el análisis de Derrida cierto viraje se ha producido a este respecto en Las palabras y las cosas de Foucault.

Finalmente, en tercer lugar, nos proponemos reconocer en qué medida resulta problemática la divisa foucaultiana de "desembarazarse" del modelo del 
Leviatán planteado en Defender la sociedad ${ }^{4}$. Esta problematicidad depende de que algunos de los rasgos descritos por Foucault como propios del Leviatán de Hobbes tengan la dificultad de presentarse como tales. Lo que también puede querer decir: la dificultad que el pensamiento de la soberanía pueda abandonar la escena del poder equivale también a la dificultad que pueda ser visto sólo desde la instancia del poder y del dominio. Tal es la consecuencia de un poder que no es nunca idéntico a sí mismo, o que siempre se (des) figura en su secuencia. Es por ello que cerramos este artículo en el umbral de la "lógica' del concepto de soberanía" tal y como es descrita en Canallas $y$ de la "doble y contradictoria figuración", como es descrita en el Seminario La bestia y el soberano.

\section{ZÔGRAPHIA DEL PODER}

En la segunda parte de su libro El animal que luego estoy si(gui)endo ${ }^{5}$, tras decir que desde Aristóteles hasta Lacan los filósofos y teóricos han asegurado que los animales no responden, y que según la interpretación de Platón en el Fedro, compartirían esa irresponsabilidad con la escritura, el filósofo Jacques Derrida reconocerá haber tenido interés por el Fedro y por "el tema de una animalidad de la escritura”. Este interés, como se sabe, se deja localizar dentro de la obra publicada La farmacia de Platón, en La diseminación. En lo que podría constituir una cierta aclaración, muy escueta sin duda, de este concepto de animalidad de la escritura, Derrida señala en el contexto que, de acuerdo a Sócrates, "lo terrible (deinon) de la escritura, es que al igual que [comme] la pintura (zôgraphia), las cosas que engendra y que son como [comme] seres vivos (hos zonta) no responden (275 d)." (DERRIDA, 2008, p. 69). La escritura, como la pintura, engendra cosas que son como seres vivos que no responden. No se dirá nada más aquí de esta comparación, símil o imagen que iguala o asemeja a la escritura con la pintura o zôgraphia. Ni tampoco del sentido de la secuencia en esta comparación: se habla de la escritura al igual que la pintura y no de la pintura al igual que la escritura. Todavía menos se habla de si esta secuencia puede ser seguida con facilidad y en forma segura. Se insistirá, en cambio, en que aunque se les plantee preguntas, los escritos

\footnotetext{
${ }^{4}$ Más adelante habrá que restablecer una relación con el texto original, cuyo título reza: "Il faut défendre la société". Y esto sobre la base de reconocer el posible sentido de la locución "il faut" dentro del texto de Foucault.

5 Citamos aquí la traducción al español de Cristina de Peretti y de Cristián Rodríguez, en Jacques Derrida. El animal que luego estoy si(gui)endo. (DERRIDA, 2008). Fr. (DERRIDA, 2006).
} 
callan, guardan silencio, o bien responden siempre lo mismo, lo que equivale a no responder. Dirá casi enseguida, citando algunos pasajes, que el Fedro, libro sobre la escritura, sobre la escritura autobiográfica, "es también un gran libro sobre el animal" y una especie de "diálogo de animales". Es muy avanzado el texto que Derrida volverá a hablar de zôgraphia en este libro. ${ }^{6}$ Esta vez para hablar sólo de ella en relación con el animal. En efecto, en la página 136 de la edición castellana, comentando un texto titulado "Nombre de un perro o el derecho natural" aparecido en una recopilación que homenajea al pintor Bram Van de Velde, Derrida, dirá entre paréntesis: "Como homenaje, supongo, a la figura del pintor, por consiguiente $[d o n c]$, a zôgraphia, a otra especie de animal y de perro cuyo lenguaje carece de palabras [mots]" (DERRIDA, 2008, p. 136; traducción parcialmente modificada). Se especifica en esta ocasión en qué consiste la figura del pintor sobre la base de un cierto seguimiento o consecuencia: la zôgraphia, especie de animal y de perro cuyo lenguaje carece de palabras ${ }^{7}$.

Lo que en relación con el Fedro va a decir Derrida en La diseminación es que, al no responder, al guardar silencio, o a responder siempre lo mismo,

\footnotetext{
${ }^{6}$ Aunque en la página 28 aclarará entre paréntesis que la zôgraphia designaba entre los griegos el hecho de pintar seres vivos en general y no sólo animales. Para lo que sigue en nuestro texto, esta es una importante aclaración.

${ }^{7}$ En El animal que luego estoy si(gui)endo, la cuestion de la auto-bio-grafía es una cuestión, no sólo central, sino transversal. Lo que, por lo mismo, creemos debería ser tomado en cuenta a la hora de tratar el problema de la comunidad a todo lo largo de la obra de Derrida. Y esto, al menos porque, como se va a decir allí, no hay huella de la manifestación de sí, de la auto-presentación como presente viviente, sino porque hay el más simple aparecer del "yo", como "estructura fenomenológica mínima”. En su trabajo, No hay mundo común: Jacques Derrida y la idea de la comunidad, Laura Llevadot nos muestra en qué consiste la actitud reacia de Derrida a la idea de comunidad y cuáles son los rasgos originales de su pensamiento ético y político. Comienza planteando la posibilidad de que ciertos aspectos biográficos del "niño", del "joven" y del "afamado filósofo" Derrida, relativos a su identidad y a su pertenencia, hayan dejado huella en su pensamiento. Dejando sin aclarar del todo si aquello que ha dejado huella es un mero antecedente fáctico o bien, de algún modo, ya el pensamiento al que dará lugar, Llevadot nos muestra no obstante que su efecto ("lo cierto...") es que Derrida es "uno de los que mejor supo pensar hasta el final las trampas de la identidad y la pertenencia.” (LLEVADOT, 2013, p. 549-550). Planteamos sólo dos preguntas al inicio de su texto y que puede tener una muy honda repercusión en el resto del mismo: 1) ¿No procede Llevadot precisamente como dice Derrida que procede Husserl en El origen de la geometría? Es decir, reconociendo que el pensamiento debió haber comenzado en el modo tal y como comenzó. 2) Dejando así la biografía de Derrida como un mero antecedente de su pensamiento, es decir no tomando entonces en cuenta Llevadot el problema de la historicidad, ¿no ha dejado fuera el pensamiento derridiano de la auto-bio-grafía? Quizá haya que pensar en Derrida una cierta política retrospectiva para "pensar hasta el final las trampas de la identidad y de la pertenencia". Una aproximación a este problema, y cuyo trasfondo es la relación entre universalidad y singularidad, y también, creemos, la discusión sobre la relación entre un universalismo racista y un racismo del universalismo, lo encontramos en Étienne Balibar (BALIBAR, 2007, p. 61-83).
} 
es el soberano el que es amenazado. Derrida se preguntará allí por los rasgos de semejanza (les traits de ressemblance) que en profundidad homologan la escritura a la pintura. También por el horizonte a partir del cual se anuncia su silencio común: "Ese mutismo testarudo, esa máscara de gravedad solemne y prohibida que disimula tan mal una incurable afasia, una sordera de piedra, una cerrazón irremediablemente débil a la petición del logos." (DERRIDA, 1975, p. 206). Llamadas a comparecer ante el tribunal del logos, escritura y pintura son interrogadas "como representantes supuestas de un habla [parole], como capaces de un discurso, depositarias e incluso encubridoras de las palabras [mots] que se les quiere hacer decir entonces." (DERRIDA, 1975, p. 206). Impotentes para representar dignamente el habla viva, impotentes para conversar y para responder, no son sino estatuillas, máscaras, simulacros.

Tanto la escritura como la pintura son entonces medidas con respecto su modelo. El modelo de la pintura (zôgraphia) es un modelo vivo. El de la escritura es el habla viva. Si la escritura se parece a la pintura es porque es pensada a partir de la escritura en tanto que escritura fonética, cuyo modelo reinaba sobre la cultura griega. Y lo que asemeja a ambas es precisamente la semejanza. Es en virtud de ello que Platón las reconoce como técnicas miméticas. Sólo que Platón prefiere pensarlas separadas y de acuerdo a lo que llamamos aquí una "secuencia soberana". En efecto, Derrida pondrá de relieve que a pesar de la semejanza entre semejanzas, o sea, a pesar de que la pintura y la escritura parecen ser lo mismo frente a su modelo, el caso de la escritura es más grave. La pintura es menos grave porque, como la escultura, es silenciosa y su modelo no habla; "el silencio del espacio pictórico o escultórico es, si se puede decir, normal." (DERRIDA, 1975, p. 208). El caso de la escritura es más grave porque es como imagen del habla que ella es dada. Lo que pretende imitar es más gravemente desnaturalizado que en el caso de la pintura. No sustituye una imagen por su modelo. Lo que hace es inscribir "en el espacio del silencio y en el silencio del espacio el tiempo vivo de la voz.” (DERRIDA, 1975, p. 208). Desplazando al modelo, no da imagen alguna de él y "arranca violentamente a su elemento la interioridad animada del habla". Triple alejamiento de la escritura: inmensamente alejada de la verdad de la cosa misma, de la verdad del habla y de la verdad que se abre al habla; "y por consiguiente [donc] del rey." (DERRIDA, 1975, p. 208, traducción modificada). Lo terrible, entonces, es que es siguiendo, o siendo como la pintura (zôgraphia), que la escritura está inmensamente alejada de la verdad de la cosa misma, de la verdad del habla y de la verdad que se abre al habla. Y, por consiguiente, del soberano. 
Para evitar esta consecuencia, Platón ha querido afirmar la secuencia escritura-pintura. Primero escritura, luego pintura. Esta vez en La doble sesión, Derrida dirá que en El filebo la aparición del pintor está prescrita por cierta comparación entre la relación silenciosa del alma consigo misma con un libro. Como antes, Derrida volverá a insistir en que tal comparación está fundada en la semejanza. El libro imita al alma y el alma imita al libro. Lo que es posible porque, antes incluso de parecerse entre sí, son "de esencia reproductiva, imitativa, pictórica, en el sentido representativa de esta palabra." Ahora bien, se dirá enseguida que el demiurgo pintor (zôgraphon) viene después del escritor (grammateus). Tras el escritor, el pintor dibuja en el alma las imágenes correspondientes a las palabras. Se hace notar de nuevo entonces la complicidad entre pintura y escritura en Platón. Y se observa enseguida, lo que hizo Derrida antes a propósito del Fedro, que para que una pueda ser imagen de la otra, una y otra deben ser "interpretadas como imágenes, reproducciones, representaciones, repeticiones de lo vivo, del habla viva en un caso, de la figura animal en el otro (zôgraphia).” (DERRIDA, 1975, p. 283). Se reitera así entonces lo dicho en torno al Fedro, pero esta vez para destacar que se trata en ambos de casos de imágenes, que son el retrato de otra cosa.

Se hará notar enseguida que el pintor no sólo viene después del escritor, sino que también lo sigue. Como un animal "va detrás de éste, sigue sus pasos, su vestigio, su pista."Luego, es como semejanza, como imagen, y en primer lugar como zôgraphia, que la escritura sigue a su vez muy de cerca, como un animal inaparente y ya sin imagen, a la voz. Y por consiguiente, al soberano. Derrida dirá que la pintura es algo más que la ilustración que se añade, representándolo, adornándolo, "al libro del discurso del pensamiento interior." Ella actúa "como el revelador puro de la esencia de un pensamiento y de un discurso definidos como imágenes, representaciones, repeticiones." (DERRIDA, 1975, p. 284). ¿Por qué? Porque si "el logos es en primer lugar imagen fiel al eidos (figura de la visibilidad inteligible) del ser”, entonces "actúa como una pintura primera, profunda e invisible." (DERRIDA, 1975, p. 284). ${ }^{8}$ Tal es, según Derrida, la "pictoricidad esencial del logos". Es que el pintor sabe "restaurar la imagen desnuda de la cosa, tal como se entrega a la simple intuición, tal como se deja ver, en su eidos inteligible o su oraton

${ }^{8}$ En el inédito Entre deux coups de des hay una variante de la expresión: "El eidos (figura de la visibilidad invisible)". Dice allí: "El eidos (figura visible)" ["l'eidos (figure visible)"]. En Fuerza y significación, en La escritura y la diferencia, encontramos otra variante. Tras decir que en la metafísica heliocéntrica la fuerza cede el sitio al eidos, dice enseguida: "(Es decir, a la forma visible para el ojo metafórico)." (DERRIDA, 1989, p. 42). Cf. Derrida (1967, p. 45). 
sensible. La despoja de todo ese lenguaje sobreańadido, de esa leyenda que tiene esta vez el estatuto del comentario, de la envoltura alrededor del núcleo, de la tela epidérmica." (DERRIDA, 1975, p. 285). La zôgraphia y el logos tienen así una estrechísima y extraña relación. Configurando la posibilidad de una especie de zoo-logía o zoo-lógica. Es que uno puede ser el suplemento del otro. Son imágenes uno del otro y por ello se pueden suplir. Por lo mismo es que la escritura como la pintura, como pintura o zôgraphia, puede amenazar más que nunca a la voz. Y por consiguiente al soberano.

Planteada entonces en el marco de la semejanza, la secuencia soberana o que sirve al soberano ya no se deja seguir fácilmente. El pintor que viene después del escritor lo sigue a su vez. Luego, lo que parece ser el contrato inicial por el cual el pintor debe limitarse a ilustrar el orden del discurso y renunciar a una animalización que como nos damos cuenta ya no se puede seguir, se revela como habiendo sido parte desde siempre de un cierto fuera-de-la-ley. En El animal que luego estoy si (gui)endo Derrida ha hecho notar que las consecuencias de ir tras el animal son que él viene antes siguiéndonos, rodeándonos. No se puede ir tras el animal, para cazarlo, adiestrarlo o domesticarlo, sin seguirlo, sin su herencia, sin formar parte de su sucesión. En La diseminación la pintura (zôgraphia), imagen de la figura animal, sigue como escritura muy de cerca al habla viva que, a su vez, sigue muy de cerca al pensamiento, por consiguiente también al soberano. Una zoo-logía o zoo-lógica, si es que no una bio-logía o una bio-lógica, parece anunciar así tempranamente una zoo-política o una bio-política. Es en la auto-afección absoluta de la proximidad de la voz y del pensamiento, de la voz y del pensamiento del soberano, que se oblitera la (no-) imagen que los ofusca. Sin embargo, no se puede contar con esta auto-afección soberana sin que la zôgraphia y la figura animal, que deben garantizarla, puedan a su vez desfigurarla.

\section{VIDA Y POLITICIDAD MÁs ALLÁ DE LA INSTANCIA DEL PODER Y DEL DOMINIO}

En lo que sigue, intentamos aproximarnos a esa posibilidad a partir de la objeción que le ha planteado Derrida a Giorgio Agamben en el sentido de que no parece posible, ni en Aristóteles, ni apoyándose en Foucault, consagrar la separación entre zôê y bios como separación entre vida desnuda (humana, animal o divina) y vida política en general. Como tampoco parece posible sostener que sólo recientemente con la modernidad tiene lugar la articulación entre ambas. Una discusión con Foucault y su relación con Freud tendrían que 
situarnos ante la posibilidad de una relación entre vida y politicidad más allá de la instancia del poder y de dominio.

Como se sabe Giorgio Agamben en su libro Hommo sacer: el poder soberano y la nuda vida I, ha querido poner en juego la diferencia entre vida desnuda como zôê, que "expresaba para los griegos el simple hecho de vivir, común a todos los seres vivos (animales, hombres y dioses)", y bios "que indicaba la forma o manera de vivir propia de un individuo o un grupo." (AGAMBEN, 1998, p. 8). Que se hable aquí de los griegos es para comenzar a señalar que a partir de la modernidad esta distinción se volverá mucho más difusa. Agamben se apoyará en un pasaje de La voluntad de saber de Foucault en que éste se refiere a Aristóteles. Antes de citar ese pasaje, Agamben ha dicho, a propósito de la definición del hombre como politikon zoon, que

político no es un atributo del viviente como tal, sino una diferencia específica que determina el género zoon (inmediatamente después, por lo demás, la política humana es diferenciada de la del resto de los vivientes porque se funda, por medio de un suplemento de politicidad ligado al lenguaje [zoon logon echon], sobre una comunidad de bien y de mal, de justo y de injusto, y no simplemente de placentero y de doloroso). (AGAMBEN, 1998, p. 11).

Enseguida dirá que si Foucault se refiere a esta definición de Aristóteles al final de La voluntad de saber es para sintetizar "el proceso a través del cual, en los umbrales de la vida moderna, la vida natural empieza a ser incluida, por el contrario, en los mecanismos y los cálculos del poder estatal y la política se transforma en bio-politica." (AGAMBEN, 1998, p. 11). Ahora bien, se sabe cómo Derrida en la duodécima sesión del seminario La bestia y el soberano (EHESS, marzo del 2002), va a cuestionar tanto la posibilidad de distinguir entre vida como zôe y política en Aristóteles como la posibilidad de hacer comenzar su no distinción con la modernidad. En relación con lo primero, como mostraré enseguida, interpreta el pasaje de Foucault de La voluntad de saber de manera distinta a como lo hace Agamben y confronta a Foucault con éste. Esta interpretación de Foucault nos interesa sobre todo. Pero haré esto no sin mencionar antes lo que se supone es, Derrida sigue hasta cierto punto a Heidegger, la crítica de Derrida del concepto de "la vida como sólo la vida" implicado en el concepto de zồ como "vida desnuda" en Agamben.

A propósito de esta crítica lanzada por Heidegger contra un cabezota que dice tonteras (bêtises) consiste según Derrida en "creer que algo tiene un 
sentido propio y único: la vida es la vida, punto, ésta es mi opinión y creo en ella." (DERRIDA, 2010, p. 359). Al contrario para Heidegger el ser de la vida es al mismo tiempo la muerte. Derrida hará notar inmediatamente su distancia con Heidegger. Toma distancia con respecto a que sólo el hombre, o sólo el Dasein, es "el único que tiene una relación de experiencia con la muerte, con el morir, con el 'sterben' como tal, con el suyo propio", "mientras que el animal, por consiguiente ese otro viviente (zôôn) al que se denomina animal, la palma [creve] pero que no muere jamás." (DERRIDA, 2010, p. 360). Para Derrida no es seguro que el hombre tenga una experiencia de la muerte como tal. Como tampoco es seguro que se pueda decir que el animal está privado de ella. En todo caso, la disputa con Heidegger, con su discurso sobre el animal, sobre la bestia como "carente de mundo" (weltarm) es aplazada, también con Heidegger, sobre todo en su Introducción a la metafísica, a favor de la discusión con Agamben, y también con Foucault.

Brevemente. Heidegger ha dicho que la definición del hombre relacionada con el concepto de animal racional (así como zoon legon echon en Aristóteles) es tardía, tardía con respecto a la "forma originaria" de "la relación entre logos y physis." (DERRIDA, 2010, p. 371). Si aquella definición ha impuesto su dominio, su señorío, también su soberanía, sobre el ser, volviéndose más fuerte que el ser, Derrida sostiene que para Heidegger la forma originaria del legein o el logos "como reunión, como Sammlung o Versammlung" es también ya un despliegue de fuerza y de violencia. Entonces "el logos ya tiene el carácter violento de un predominio [Durchwalten]" de la physis, y ésta es ese Gewalt. En fin, el logos pertenece ya desde siempre al orden del poder, de la fuerza, de la violencia; de la Gewalt. Explica Derrida: "Fuerza, violencia, potencia, poder, autoridad: con frecuencia poder político legítimo, fuerza del orden: walten es reinar, dominar, ordenar, ejercer un poder a menudo político; la soberanía, el ejercicio de la soberanía pertenece al orden del walten y de Gewalt." (DERRIDA, 2010, p. 373).

Nos aproximamos decisivamente al problema de la soberanía. Pero no sin haber señalado en qué sentido Heidegger parece abrir la cuestión o el cuestionamiento acerca de una physis originaria que está lejos de ser idéntica a sí misma, es decir está atravesada por una cierta disensión originaria. No estamos lejos tampoco de Cogito e historia de la locura en La escritura y la diferencia (DERRIDA, 1989, p. 49-89). Pero no me desvío. Lo que está en juego es la dificultad de cualquier intento de restringir lo vivo a lo puramente 
vivo, o a la vida desnuda, como quiere Agamben. En lo que está implicada cierta diferencia entre éste y lo que dice Foucault en La voluntad de saber.

Después de haber mostrado que Agamben no dejó de reconocer en Aristóteles la existencia de una zôe no desnuda a propósito de Dios y de que por lo mismo éste "ya había pensado a su manera la posibilidad de que la política, la politicidad, pudiese calificar, incluso apoderarse, en ciertos casos como el del hombre" (DERRIDA, 2010, p. 382), Derrida procede a decir, en el marco de una primera observación de tipo lógico a lo que dice Agamben, que no ve ninguna "diferencia clara y necesaria" entre lo que para Agamben es la diferencia entre el "atributo del ser vivo como tal" y la "diferencia específica que determina al género zôon". Para Derrida lo que dijo "muy bien” Aristóteles es que "el atributo de la vida desnuda del ente llamado hombre" es político, lo cual "es su diferencia específica". A este respecto Foucault ha dicho lo siguiente (es el pasaje de La voluntad de saber que Derrida cita textualmente pero ańadiendo una cursiva): "El hombre, durante milenios, ha seguido siendo lo que era para Aristóteles: un animal vivo y, además, capaz de una existencia política; el hombre moderno es un animal, en la política del cual su vida de ser vivo está en cuestión." (DERRIDA, 2010, p. 384). ${ }^{9}$ Destacando la palabra "además", agrega que lo que dice Foucault es "el eco" de lo que muy bien dice Aristóteles pareciendo no obstante oponer con un en cuestión "dos posibilidades que, por mi parte, encuentro perfectamente recíprocas, o reciprocables, o complementarias." (DERRIDA, 2010, p. 384). La segunda observación de Derrida está centrada en la sugerencia que el bio-poder no es nuevo, que si bien hay novedades en el bio-poder que son inauditas, ni el biopoder ni el zoo-poder son algo nuevo. Y que es en el propio Agamben que esto encuentra apoyo cuando éste reconoce que la biopolítica es algo archi-antiguo, lo que implica un vínculo con la idea de soberanía. ${ }^{10}$

Lo que Derrida sugiere aquí, que Foucault no parece suscribir del todo lo que dice Agamben, es sin duda muy poco para hacerse una idea de lo que hay en Foucault de politicidad de la vida antes de la modernidad y en Aristóteles mismo. La mayor parte del tiempo en este texto Derrida ve a Agamben junto a Foucault defendiendo una especificidad moderna. Habría en ello implicado una "tentación común" de una historia lineal a la que resulta muy difícil renunciar ("la modernidad que viene después de la edad clásica, las epistemes que se suceden y se tornan caducas unas a otras”, etc.) pese a

\footnotetext{
${ }^{9}$ Cf. Foucault (1976, p. 188; AGAMBEN, 1998, p. 11).

${ }^{10}$ Cf. Agamben (1998, p.15-16).
} 
que la periodización misma aparece puesta en cuestión ("una modernidad que no sabemos dónde comienza y donde termina, una edad clásica cuyos efectos todavía son perceptibles, una antigüedad griega cuyos conceptos están más vivos y sobrevivientes que nunca", etc.). Para Derrida, no obstante, estos discursos resultan "muy interesantes" en la medida en que, "en primer lugar, se dirigen a lo más vivo de lo que nos importa en este seminario, el poder soberano, la vida y la muerte, la animalidad, etc." (DERRIDA, 2010, p. 386). Recomienda entonces "releer de cerca [il faut relire de près], entre otras cosas (como lo hice hace poco, aquí y en otros lugares, no quiero volver sobre eso), acerca del poder soberano como poder de vida y de muerte, en $\mathrm{La}$ voluntad de saber, el último capítulo titulado Derecho de muerte y poder sobre la vida." (FOUCAULT, 2002b, p. 386). Lo seguirá una breve referencia a Ser justo con Freud, conferencia de 1991 recogida en Resistencias del psicoanálisis en donde interroga e interpreta dicho capítulo. La antecede una conferencia inédita del año 1986 que, en parte, está alojada en el texto recién aludido y su interpretación, y cuyo título es: Más allá del principio del poder (DERRIDA, 2010, p. 386, nota 36). ${ }^{11}$

Hago notar de paso que dentro de estos "otros lugares" el editor del Seminario La bestia y el soberano señala en nota que, "entre otras", se trata de la primera sesión del seminario sobre La pena de muerte, realizada el 8 de diciembre de 1999 (seminario cuyo primer volumen ha sido publicado en Galilée el año 2012 y en donde se hace referencia a Vigilar y castigar). Se podría quizás agregar aquí El animal que luego estoy si(gui)endo, fruto de una conferencia de 1997. Aunque no hay la más mínima referencia a Foucault, es posible encontrar muchas conexiones. En todo caso, en cuanto a que lo que importa en este seminario es, entre otras cosas, el poder soberano, la vida y la muerte, la animalidad, es La voluntad de saber lo que, según Derrida, "hay que releer de cerca", en particular el capítulo titulado Derecho de muerte y poder sobre la vida.

Pese a la importancia que pueda tener este texto, por una cuestión del necesario espacio que habría que brindarle a un texto que se merece un artículo completo me limito a decir tan sólo un par de cosas en torno a su lectura en Ser justo con Freud. Este texto de Derrida nos interesa sobre todo porque está centrado en la relación entre Foucault y Freud, y en lo

\footnotetext{
${ }^{11}$ Tenemos a la vista la traducción de Javier Pavez, entiendo que todavía inédita, pero consultable en academia.edu. Au-delà du príncipe du pouvoir apareció en el volumen (In)actualités de Derrida de la Revista Rue Descartes, v. 3, n. 82, p. 4-13, 2014..
} 
que conduce, a través de esta relación, a una soberanía pensada más allá de la instancia del poder y del dominio. Ahora bien, en el horizonte de lo que va a ser la lectura y la interpretación de La voluntad de saber quiero señalar, en primer término, que todavía no acabo de entender que Derrida no haya hecho mención de la expresión "violencia soberana" allí donde, citando, comentando y hasta parafraseando los últimos párrafos del primer tomo de la Historia de la locura, considere el retorno de Freud pero no la expresión "violencia soberana". Es como si de la soberanía, y de la violencia soberana, Foucault sólo hablara a partir de La voluntad de saber.

En efecto, al final del capítulo Médicos y enfermos, en el último párrafo, que es también el último párrafo de la segunda parte del libro, Foucault dirá que "es preciso ser justo con Freud", y tras mencionar algunos de sus trabajado va a decir: "Hay allí la violencia soberana de un retorno." (FOUCAULT,1972, p. 360). Analizando esta especie de epílogo en la que se haya este pasaje, pasaje que es también un pasaje de la relación de Foucault con Freud, Derrida destaca la resistencia del psicoanálisis a la psicología como resistencia a la conversión de la sinrazón en enfermedad, como restablecimiento del diálogo con la sinrazón abierta en la época clásica. Freud retoma entonces el diálogo. Citará enseguida el último párrafo entero. Tras lo cual hablará, sin mencionar la expresión "violencia soberana", de la violencia impuesta sobre la sinrazón como imposición de una máscara. Es que "la psicología positivista habría entonces enmascarado [masqué] la experiencia de la sin razón: imposición de una máscara, disimulo violento del rostro, de la verdad o de la visibilidad. Se pierde así la relación con una cierta verdad de la locura." (DERRIDA,1997, p. 120). Mientras que el psicoanálisis, "por el contrario, rompe con la psicología al hablar con la sinrazón que habla en la locura", retorna por tanto "[en virtud de esa palabra intercambiada, no a la edad clásica en sí (que, a diferencia de la psicología, ha determinado perfectamente la locura como sinrazón, aunque para excluirla o encerrarla), sino a ese desvelo de la época clásica que aún lo asediaba." (DERRIDA, 1997, p.120). Dejo hasta aquí el primer aspecto, pero no sin dejar planteado las siguientes preguntas: ¿por qué no hablar de la "violencia soberana" de este retorno a la sinrazón sin exclusión en confrontación con la violencia de la psicología de la que aquí se habla a partir de la relación entre el enmascaramiento y la animalización profusamente desarrollada en el capítulo Los insensatos? (FOUCAULT,1972, p. 164-165). ¿Qué hay en la Historia de la locura en cuanto a la relación entre soberanía, violencia y animalidad? 
El segundo aspecto, que retoma el anterior, es el siguiente: el Freud que según Derrida se muestra "hospitalario" con la locura es el Freud que "se explica con la muerte" (DERRIDA, 1997, p. 149). Es el Freud de Más allá del principio del placer (DERRIDA, 2001). Derrida hace notar que en El nacimiento de la clínica (publicada en francés en 1963), en la experiencia de la muerte como "finitud originaria", Foucault integra a Freud a "la modernidad desde la cual se escribe Histoire de la folie [publicada por primera vez en 1961]." (DERRIDA, 1997, p. 149). Enseguida seńala que a partir de Las palabras y las cosas (publicada en 1966), Freud aparece situado fuera del campo de las ciencias humanas en la medida en que, Derrida cita,'restituye el saber del hombre a la finitud que lo funda'. (DERRIDA, 1997, p. 151-152). Una intimidad del psicoanálisis con la locura es lo que ahora se afirma, si bien no sea más que para reconocer su límite. Lo que en definitiva será puesto en tela de juicio en la intimidad con la locura será la posibilidad de subjetivar: "Su intimidad con la locura por excelencia, dirá Derrida, es la intimidad con lo menos íntimo, una no-intimidad que lo lleva a lo más heterogéneo, a lo que en ningún caso se deja interiorizar, ni siquiera subjetivar: ni alienado -diría yo-, ni inalienable.” (DERRIDA, 1997, p. 152). Se destacará enseguida que el psicoanálisis aporta un descubrimiento "en los confines exteriores de la representación", lo que entraña una relación con "las figuras concretas de la finitud". Luego, y ya esta vez en relación con Más allá del principio del placer de Freud y "en el horizonte de un más allá del principio del placer" (DERRIDA, 1997, p. 164), Derrida se preguntará cómo Foucault habría situado en "su discurso sobre el poder o sobre los poderes", aquella pulsión de dominio de la que habla Freud, muy especulativamente, y que problematiza, "en su mayor radicalidad, la instancia del poder y del dominio." (DERRIDA, 1997, p. 165). Con lo que se sugiere aquí habría que examinar en qué consiste aquello que en La tarjeta postal se llama la "soberanía absoluta" del principio del placer, y también aquello que, como su "ventrílocuo", lo hace hablar (DERRIDA, 2001, p. 280). Observamos, de paso, que la cuestión de la "problematización" está en el centro de la pequeña conferencia llamada Más allá del principio del poder.

3 EL PODER SOBERANO, LA MULTIPLICIDAD Y LA POSIBILIDAD DE DESEMBARAZARSE DEL MODELO DEL LEVIATÁN: EL PROBLEMA DE LA DOBLE Y CONTRADICTORIA FIGURACIÓN

Intentamos discernir ahora lo que podría llegar a ser cierta problematización de la instancia del poder y del dominio a propósito del Leviatán de Hobbes. De fondo, está la cuestión del paso de la teoría del poder 
como soberanía a la teoría del poder como biopolítica. Es decir, el problema o lo problemático de este paso.

En La voluntad de saber (publicada en francés en 1976), Foucault hablará de la soberanía como el derecho de vida y muerte, o más precisamente, como "el viejo derecho de hacer morir o dejar vivir." (FOUCAULT, 2002b, p. 167). Pero, desde el comienzo del capítulo Derecho de muerte y poder sobre la vida, la soberanía así definida es presentada según una forma históricamente atenuada, como una especie de "derecho de réplica". No siendo ya un privilegio absoluto, los teóricos clásicos darían cuenta de ello, el derecho de vida y de muerte según Foucault "está condicionado por la defensa del soberano y su propia supervivencia." (FOUCAULT, 2002b, p. 163). Lo que ha comenzado a reemplazarla es "el poder de hacer vivir o de rechazar en la muerte" (FOUCAULT, 2002b, p. 167; traducción modificada y con su cursivas, del autor, restauradas). Es la era del "bio-poder" en la que "la vieja potencia de muerte, en la cual se simbolizaba el poder soberano, se halla ahora cuidadosamente recubierta por la administración de los cuerpos y la gestión calculadora de la vida." (FOUCAULT, 2002b, p. 169). Veamos ahora brevemente en qué consiste este recubrimiento cambiando de libro pero no de año: en el libro Il faut défendre la société, particularmente en el curso del $14 \mathrm{de}$ enero de $1976^{12}$.

Puesto que nos detendremos en la visión de Foucault sobre el Leviatán de Hobbes, sobre lo que en relación con la "teoría de la soberanía", es su "modelo" del poder, su "esquema", haremos esto teniendo a la vista una cierta confrontación con lo que es, por otra parte, la necesidad planteada por Derrida de considerar la soberanía política en Hobbes como aquello que se eleva por encima de la bestia, por encima de la vida animal, pero también como animalidad o naturalidad humana. Indagaremos en qué consiste una protestatalidad "conforme a la lógica técnica o protética de un suplemento que suple a la naturaleza añadiéndole un órgano artificial." (DERRIDA, 2010, p.47). Nos preguntamos si Derrida sigue aquí como (a) un animal a Foucault.

Lo que nos interesa, primeramente, es el alcance de la necesidad planteada por Foucault de desembarazarse del "modelo del Leviatán” para

\footnotetext{
${ }^{12}$ Aunque citaremos la traducción al castellano de Fondo de Cultura Económica, no dejaremos de sospechar de una versión que, a nuestro entender, ha traducido demasiado un título que a su vez es un texto, una cita y una firma. El "Il faut" que preside el título francés en ningún caso creemos que pueda ser obliterado en un texto que no parece querer ahorrarse esta locución. Esto es precisamente el caso con el tema que nos interesa.
} 
estudiar el poder. Es esta una necesidad que no podría tener sentido sin la dificultad planteada por la misma persistencia del modelo en un mundo que ya sabe de su retirada y del peligro que entraña pensar el poder sobre la base de su vigencia. ${ }^{13}$ Para Foucault es necesario (il faut) estudiar el poder "fuera del campo delimitado por la soberanía jurídica y la institución del Estado" (FOUCAULT, 2000, p. 42) ${ }^{14}$ y analizarlo "a partir de las técnicas y tácticas de dominación" (FOUCAULT, 2000, p. 42). Lo que implica situar a este análisis en la misma línea metódica de las investigaciones que Foucault ha desarrollado precedentemente (poder psiquiátrico, sexualidad de los niños, sistema punitivo, etc). Dada la importancia y la envergadura de este asunto, seamos más explícitos. ¿De qué es necesario desembarazarse? Foucault lo dice antes que todo lo que se ha dicho: "De ese modelo de un hombre artificial, a la vez autómata, fabricado y unitario, que presuntamente engloba a todos los individuos reales y cuyo cuerpo serían los ciudadanos pero cuya alma sería la soberanía.” (FOUCAULT, 2000, p. 42). ¿Por qué es necesario estudiar el poder fuera del campo delimitado por la soberanía jurídica y el Estado? Foucault lo dirá un poco después, justo antes de enunciar y exponer los "cuatro papeles" que desempeńó la teoría de la soberanía: porque la teoría jurídico-política de la soberanía que data de la Edad Media y del resurgimiento del derecho romano, que se construyó en torno a la monarquía y el monarca, "es la gran trampa en que se corre el riesgo de caer cuando se quiere analizar el poder." (FOUCAULT, 2000, p. 42). Digamos, para volver rápidamente al Leviatán, que esta trampa está vinculada al hecho que ha sobrevivido a su temprano reemplazo por lo que Foucault llama el "poder disciplinario". Tras preguntarse por qué la teoría de la soberanía persistió

\footnotetext{
${ }^{13}$ La persistencia del poder en términos de soberanía no se va a limitar en su peligrosidad, como se va a señalar aquí, a que, por ejemplo, enmascare ideológicamente los mecanismos de dominación del poder disciplinario, haciendo pensar que los derechos de los individuos tienen una real y efectiva vigencia, sino que también esa persistencia se va a hacer sentir, más peligrosamente, en la inscripción del racismo, que "existía desde hace mucho tiempo atrás." (FOUCAULT, 2000, p. 230), en el Estado. Simone Regazzoni, en el artículo ya citado, observa que Foucault "reintroduce precisamente la lógica de la soberanía que había intentado excluir." (REGAZZONI, 2015, p. 226). Con todo, estamos tentados a ver en la locución il faut, que es también la locución de la frase de Foucault que hace de título del libro y que la versión en castellano ha amputado, la dificultad, o la problematicidad, con la que no deja de contar Foucault al querer dar cuenta de la historicidad del fenómeno del poder. En este sentido, nos parece que esta dificultad resiste como dificultad incluso si se intenta, como nos parece procede Foucault aquí, a super-estrucuralizar la soberanía a título de ideología. En todo caso, habría que tomar en cuenta lo que Guillaume Sibertin-Blanc, señala en el sentido de que Foucault acusa recibo de las transformaciones de la soberanía cuando es re-movilizada en el interior de la racionalidad biopolítica (SIBERTIN-BLANC, 2016).
}

${ }^{14}$ Traducción parcialmente modificada. Cf. Foucault (1997, p. 30). 
como ideología y "principio organizador de los grandes sistemas jurídicos" (FOUCAULT, 2000, p. 44), Foucault se da dos razones: de un lado ella sirvió como instrumento crítico contra la monarquía y contra los obstáculos puestos al desarrollo de la sociedad disciplinaria. De otro lado, como base de la institucionalidad jurídica la teoría de la soberanía permitió "superponer a los mecanismos de la disciplina un sistema de derecho que enmascaraba sus procedimientos, que borraba lo que podía haber de dominación en la disciplina y, por último, que garantizaba a cada uno el ejercicio, a través de la soberanía del Estado, de sus propios derechos soberanos." (FOUCAULT, 2000 , p. 44). Así lo que tiene lugar como democratización de la soberanía es al mismo tiempo lastrado en profundidad por los mecanismos de coerción disciplinaria. Es que "las coacciones disciplinarias debían ejercerse a la vez como mecanismos de dominación y quedar ocultas como ejercicio efectivo del poder." (FOUCAULT, 2000, p. 44-45).

En cuanto a la necesidad de desembarazarse del Leviatán Foucault dice a modo de consigna (consigne) que se trata de analizar el poder sin tomarlo por "el lado interno", por su intención o su finalidad, a menos que su intención esté investida enteramente de prácticas reales y efectivas. La pregunta por el modo como aparece el soberano en lo alto debe ser reemplazada por el intento de saber el modo "cómo se constituyen poco a poco, progresiva, real, materialmente los súbditos, el sujeto, a partir de la multiplicidad de los cuerpos, las fuerzas, las energías, etc.” (FOUCAULT, 2000, p. 37). Lo que Hobbes en el Leviatán no quiso hacer es precisamente captar "la instancia material del sometimiento en cuanto que constitución de los súbditos”. Recordando enseguida el "esquema del Leviatán", el frontispicio del libro de Hobbes, Foucault se refiere al Leviatán "en cuanto hombre fabricado". Se trata de "la coagulación de una serie de individualidades separadas, que se reúnen por obra de cierto número de elementos constitutivos del Estado." (FOUCAULT, 2000, p. 38). En seguida, una referencia orgánica, corporal, cuyo centro soberano es el alma del Leviatán. Pero "en el corazón o, mejor, en la cabeza del Estado, existe algo que lo constituye como tal, y ese algo es la soberanía, de la que Hobbes dice que es precisamente el alma del Leviatán." (FOUCAULT, 2000, p. 38). Sin abandonar el recurso al cuerpo, y a su constitución como sujetos, es lo periférico y lo múltiple lo que hay que estudiar en vez de plantear el problema de un alma central. Pues, "en vez de plantear el problema del alma central, creo que habría que tratar de estudiar -y es lo que intenté hacer- los cuerpos periféricos y múltiples, esos cuerpos constituidos, por los efectos de poder, como sujetos.” (FOUCAULT, 2000, p. 38). 
¿[P]or qué la soberanía política, el soberano o el Estado o el pueblo son presentados tan pronto como aquello que se eleva, por la ley de la razón, por encima de la bestia, por encima de la manifestación de la bestialidad, y tan pronto (o simultáneamente) como la manifestación de la bestialidad o de la animalidad humana, dicho de otro modo, de la naturalidad humana? (DERRIDA, 2010, p. 47).

Lo que está en juego en esta pregunta es lo que va a llamar el Seminario La bestia y el soberano una "doble y contradictoria figuración", a la que sólo haremos referencia después. Si esta pregunta que formula Derrida es pertinente y atañe directamente al Leviatán, entonces, éste no es ni puramente fabricado, ni puramente unitario, ni puramente central. Tres rasgos entonces, para concluir:

1. No es puramente fabricado porque tiene a Dios por modelo, es decir su modelo absoluto es lo que está fuera de contrato y de institución: se dirá primeramente que la soberanía es "cualquier cosa menos natural". No es sino el producto de un artificio, es un artefacto como producto del hombre. Es la figura de un monstruo. De un hombre animal, de un monstruo animal más fuerte que el hombre natural. Es "una prótesis gigantesca" que protege al ser vivo. Derrida hablará de "protestatalidad" para designar "una máquina estatal y protética" destinada a "prolongar, remedar, imitar, reproducir incluso hasta en el más mínimo detalle al ser vivo que la produce.” (DERRIDA, 2010, p. 49). La soberanía, las leyes, la ley y el Estado no son en nada naturales. Son prótesis que se han establecido por contrato o convención. Cuestión puramente humana, según Hobbes no se puede hacer contrato ni con Dios ni con las bestias. Pero para Derrida "la esencia antropológica de la protestatalidad" se hace, desde el comienzo del Leviatán, "según el modelo divino". El Leviatán imita el arte natural de Dios. Dios, entonces, es el modelo de la soberanía, pero de una soberanía fuera de contrato. Más allá de la soberanía, como "el soberano del soberano" (DERRIDA, 2010, p. 74). Es lo que se da a pensar, siguiendo a Schmitt, en relación con la excepción: "lo que hace la ley exceptuándose de la ley.” (DERRIDA, 2010, p. 74). ¿No se ha mencionado ya también al animal aquí? Esperemos un poco.

2. No es puramente unitario o indivisible porque es construible, es protético: Derrida dirá sin equívocos que la "protestatalidad plantea [pose] la indivisibilidad absoluta de la soberanía” (DERRIDA, 2010, p. 70). Sin esta indivisibilidad no hay soberanía. Y es por esta indivisibilidad que, según 
Hobbes, se puede perseguir y matar al animal. Pero la soberanía es una "alma artificial”, protético. La estructura protética del Leviatán es "su estructura convencional, tética, contractual”, de lo que se sigue que

la ley, la soberanía, la institución de Estado son históricas y siempre provisionales, digamos deconstruible, por esencia frágiles o finitas o mortales, aunque la soberanía se plantee como inmortal. Se plantea como inmortal e indivisible precisamente porque es mortal, y divisible, estando destinado al contrato o la convención a garantizarle lo que no tiene o no es naturalmente. (DERRIDA, 2010, p.66).

Su inmortalidad depende de la prótesis que le asegura una supervivencia indefinida.

3. No es puramente central porque teniendo a Dios por modelo tiene a su vez por modelo a la bestia. Ambos fuera de contrato: el alma artificial, protésica, histórica, lo es de un animal artificial que imita o sigue la naturaleza como creación de Dios. Y ya sabemos que así Dios es el soberano del soberano, el fuera de la ley de la ley. Es siguiendo a este modelo teológico que se excluye del contrato tanto a Dios como a la bestia. Y lo que así se sigue, se continúa, se hereda, no es sino este fuera de contrato.

Dios está más allá del soberano pero como soberano del soberano. Lo que equivale a decir que ese modelo teológico del Leviatán, obra del arte o del artificio humano que imita el arte de Dios, ese modelo teológico de lo político excluye de lo político todo aquello que no es lo propio del hombre, tanto Dios como la bestia, Dios como la bestia. (DERRIDA, 2010, p.74; la cursiva es de Derrida).

No hay cómo no animalizar al soberano. O también: no hay cómo no salir de la instancia del poder y del dominio.

Es también la cuestión de la figuración, de la "doble y contradictoria figuración" entre la bestia y el soberano de la que se ha hablado, antes de hablar de Hobbes, en la primera sesión del Seminario La bestia y el soberano. ${ }^{15} \mathrm{O}$ también, la cuestión de la dificultad de (no) seguir (contando con) la secuencia soberana que ya podíamos reconocer en La diseminación. La bio-política o zoo-política, como ya lo dijimos, es también una bio-logía, una zoo-logía. Es lo que afecta desde el comienzo a la soberanía, al silencio soberano del que se

${ }^{15}$ Cf. Derrida (2010, p. 46-47). 
dice, en Canallas, que ya antes incluso de sustraerse del tiempo y del lenguaje, ya ha hecho cierto contrato con la temporalización infinita de la que se sustrae. Es por eso que puede decirse que la "soberanía pura", por cuya mismidad "se calla siempre en la ipseidad misma de su momento propio, el cual no puede ser sino la punta estigmática de un instante indivisible" (DERRIDA, 2005, p. 125), "no existe". Lo que en este mismo texto se llama la "lógica' del concepto de soberanía” (DERRIDA, 2005, p. 126; la palabra entre comillas en del texto), describe la violencia de una 'lógica' según la cual la soberanía abusa utilizando, y por la cual sólo puede reinar sin compartir, en su tendencia a la hegemonía imperial, en el poco tiempo de que dispone como la "soberanía misma”. Desde que la razón de la fuerza soberana es dar cuenta de todo, no hay cómo evitar que desaparezca al aparecer como la soberanía. La doble y contradictoria figuración "es siempre el comienzo de una fabulación". Por eso es posible sugerir que "el discurso político, incluso la acción política que va unida a él y que es indisociable de él", pueden estar "constituidos, incluso instaurados por lo fabuloso, por esa especie de simulacro narrativo, por la convención de algún como si histórico, por esa modalidad ficticia del 'contar historias' que se llama fabulosa o fabulística.” (DERRIDA, 2010, p. 58).

TRUJILLO, I. Sovereignty beyond power and dominance: on the biopolitics of Jacques Derrida. Trans/formlação, Marília, v. 41, n. 2, p. 73-94, Abr./Jun., 2018.

ABSTRACT: In the present article we try to find in the Derrida of La dissemination (1972) a certain bio-political thinking that includes the figure of the animal, and in relation to which the concept of sovereignty can be thought of in a way that goes beyond instances of power and domination. The Seminar The Beast and the Sovereign, published posthumously, seems to be the Derrida's most finished expression of this line of thinking. First we follow Derrida's discussion of painting as zoography in La dissemination. On the basis of a deconstruction of what we call here the "sovereign sequence", we analyze the relationship between sovereignty and "the animality of writing" as a corollary of biopolitics or zoopolitics. Second, we explore Derrida's discussion with Agamben and with Foucault on the concept of life, and discuss a politicity of life that includes animality and that can be situated beyond power and domination. Third, we compare Foucault's and Derrida's ideas on sovereignty as expounded in Hobbes' Leviathan. Three question raised by Foucault about the Leviathan (State) are treated: whether it is purely manufactured, whether it is purely unitary, and whether it is purely central. In conclusion, we return to the initial problem of zoography and what Derrida calls "the double and contradictory figuration". A concept of sovereignty that includes animal figuration can not 
avoid de-figuration and, consequently, it is no longer possible to think of sovereignty only in terms of the political.

KEYwORDs: Biopolitics. Sovereignty. Zoography. Derrida. Foucault.

\section{REFERENCIAS}

AGAMBEN, G. Homo sacer: el poder soberano y la nuda vida I. Valencia: PreTextos, 1998.

BALIBAR, E. Constructing and Deconstructing the Universal: Jacques Derrida's Sinnliche Gewissheit. In: DOUZINAS, C. (Ed.). Adieu Derrida. London: Pallgrave Macmillan, 2007. p. 61-83.

BISET, E. Deconstrucción de la biopolítica. Pleyade, Revista de Humanidades y Ciencias Sociales, n.17, p. 205-222, Enero-Junio 2016. $144,2008$.

. Soberanía, animalidad y política. Nombres. Córdoba, año XVII, n. 22, p. 125-

. Violencia, justicia y política: una lectura de Jacques Derrida. Córdoba:

Eduvim, 2012.

DERRIDA, J. La diseminación. Barcelona: Fundamentos, 1975.

. La escritura y la diferencia. Barcelona: Anthropos, 1989.

. Resistencias del psicoanálisis. Buenos Aires: Paidós, 1997.

. La tarjeta postal. Buenos Aires: Siglo XXI, 2001.

- Canallas: dos ensayos sobre la razón. Madrid: Trotta, 2005.

. L'animal que donc je suis. París: Galilée, 2006.

. Séminaire La bête et le souverain. París: Galilée, 2008. V. I.

. Seminario La bestia y el soberano. Buenos Aires: Manantial, 2010.

. Séminaire La peine de mort. París: Galilée, 2012. V. I.

FOUCAULT, M. Histoire de la folie à l'âge classique. París: Gallimard, 1972.

. Histoire de la sexualité I: la volonté de savoir. París: Gallimard, 1976.

. Defender la sociedad. México: FCE, 2000.

. Las palabras y las cosas. Buenos Aires: Siglo XXI, 2002a.

. Historia de la sexualidad. 1: la voluntad de saber. Buenos Aires: Siglo XXI, 2002 b.

. El nacimiento de la clínica. Buenos Aires: Siglo XXI, 2003 a. 
. Vigilar y castigar. Buenos Aires: Siglo XXI, 2003b.

GALIAZO, E. Deconstrucción, política y animalidad. In: PENCHASZADEH, A. P.; BIDET, E. (Comp.). Derrida Politico. Colihue, Buenos Aires, 2015. p. 115-131.

LLEVADOT, L. No hay mundo común: Jacques Derrida y la idea de comunidad. Isegoría: Revista de Filosofía Moral y Política, n. 49, p. 549-566, julio-diciembre 2013.

PAVEZ, J. Vida espectral: deconstrucción y biopólitica. Revista Actuel Marx Intervenciones, Santiago, Lom, n. 18, p. 201-229, 2015.

REGAZZONI, S. Derrida y la deconstrucción de lo biopolítico. Trudução Renata Prati. In: PENCHASZADEH, A. P.; BIDET, E. (Comp.) Derrida politico, 2015. p. 221-235.

SIBERTIN-BLANC, G. Raza, población, clase: discurso histórico-político y biopolítica del capital de Foucault a Marx. Revista Actuel Marx Intervenciones, n. 21, 2016 (por aparecer).

Recebido: 28/02/2017

Aprovado: 20/10/2017 